\title{
Extent of Adoption and Adoption Gaps amongst the Mustard Growers (B. F. \& NB. F.) regarding Recommended Mustard Production Technology
}

\author{
S.R. Meena ${ }^{1 *}$ and Y.K. Sharma ${ }^{2}$ \\ ${ }^{1}$ Department of Extension Education, S.K.N. College of Agriculture, (SKNAU), Jobner, India \\ ${ }^{2}$ Department of Extension Education, College of Agriculture Lalsote, SKNAU, Jobner, India \\ *Corresponding author
}

\section{Keywords}

Impact, KVK's,

Training, FLD's

DRMR Scientists,

Adoption,

Rapeseed-Mustard,

Oilseeds Crops,

Mustard Growers,

(B.F. \& NB.F.)

Recommended Mustard production technology

\section{Article Info}

Accepted:

xx August 2019

Available Online:

xx September 2019

\section{A B S T R A C T}

The present investigation was conducted in Bharatpur Region of Rajasthan state, India during the years 2014-15, 16-17. Bharatpur Region was purposively selected for the present investigation due to the following reasons: Rajasthan is rank first amongst all the states of India in terms of both area and production of rapeseeds-mustard. Rajasthan state comprises of tenth regions. In Rajasthan, the rapeseeds and mustard crop is most popular oilseeds crops cultivated in Jaipur, Alwar, Bharatpur, Dholpur, Karouli, Sawai-madhopur, Sriganganagar, Jhunjhunu and Sikar Districts. In this state, its grown on area of 25,32,330 hectares with an annual production of 32,57,987 tonnes and productivity of $1287 \mathrm{~kg} / \mathrm{ha}$. in the years $2015-16$. Rapeseed-mustard is the most important oilseeds crops grown in rabi season in Bharatpur Region of Rajasthan. Bharatpur Region occupies first rank in area, production and productivity of rapeseed and mustard crop amongst the oilseeds crops in tenth regions of Rajasthan. It's mostly grown in five selected Districts of Bharatpur Division of Rajasthan. This region has covered 7,49,597 hectares of land. Whereas, an annual production of rapeseed and mustard crop is 10,07,502 tonnes which is very high $1344 \mathrm{~kg} / \mathrm{ha}$. as compared to average national productivity in years 2015-16. DRMR:Directorate of Rapeseed-Mustard Research station is located in near at Sewar, Bharatpur Region of Rajasthan in India. Therefore, DRMR, Sewar under Bharatpur Region was purposively selected. Front Line Demonstrations (FLDs) are being laid out regularly by the DRMR Scientists on the various farmer's field to demonstrate the production potential of rapeseeds-mustard technologies. All the recommended Practices were provided to the selected farmers. An exhaustive list of mustard growers from each selected KVKs was prepared in this way 25, beneficiary farmers and 25, non-beneficiary farmers were selected from the list available at the each KVKs head quarter. Thus, total 50 mustard growers were selected from each KVK by used the simple random sampling technique. Thus, these obtained lists, the 125 , beneficiary farmers and 125 , non-beneficiary farmers were selected regarding Recommended Mustard Production Technology in Bharatpur division. Thus, total sample sizes were consisted of 250 mustard growers from the present research study by using simple random sampling technique through proportionate. Responses were recorded in quantitative form through pre-structured interview schedule technique on the 250 selected respondents. The present study was undertaken in Bharatpur Region of Rajasthan State, to find out that the extent of adoption among-st the mustard growers on a sample size of 250 respondents. The study highlights that the maximum number, more than half of the respondents were found the total majority of farmers $136(54.40 \%)$, the majority 70 of the beneficiary farmers $(56.00 \%)$ and the majority 66 of the nonbeneficiary farmers $(52.80 \%)$ were having from medium level extent of adoption groups category. Further reported that the highest extent of adoption exists in package of practices likes "Seed rate \& recommended spacing" and "Irrigation management" hence, it were ranked first and second. Further recorded that the medium extent of adoption in package of practices likes "Fertilizer application", "Soil \& field preparation", "Seed treatment", "Time of sowing", "Weed management", and "Harvesting/threshing \& storage" were ranked Third, Fourth, Fifth, Sixth, Seventh and Eighth in ranks order. Further observed that the significant association for Education level, social participation, extension participation, Source of information utilized, Economic motivation, and Irrigation potentiality had positively and significantly associated with the extent of adoption. On the other hand, non-significant association for age, size of land holding and risk orientation had negatively and non-significantly associated with the extent of adoption. It indicates that the beneficiary farmers had higher extent of adoption as compared to non-beneficiary farmers amongst both the category of farmers regarding recommended mustard production technologv. 


\section{Introduction}

The Indian Council of Agricultural Research (ICAR) institutes, state agricultural universities (SAU) and Krishi Vigyan Kendras $(\mathrm{KVK})$ were set up for meeting the emerging research and education challenges. As an autonomous organization under the Department of Agricultural Research and Education (DARE), the ICAR is the apex body mandated for coordinating, guiding and managing research and education in Agriculture, Horticulture, Fisheries and Animal sciences in the Country. For implementing its research policies and programmes, the ICAR has developed a strong network of 109 institutes, 78 all-India coordinated projects \& networks and 680 KVKs spread across the Country. There are 71 State Agriculture, Veterinary, Horticulture \& Fishery Universities and 4 General Universities with agriculture faculty.

Agricultural Extension Division is one of the Subject Matter Divisions where the major activities are of Assessment and Demonstration of Technology/Products through a network of 690 Krishi Vigyan Kendras (KVKs). The Division of Agricultural Extension, ICAR, New Delhi is headed by Deputy Director General (Agricultural Extension) supported by 2 Assistant Director Generals. Krishi Vigyan Kendra (KVK) is an agricultural extension center in India. The name means "farm science center". Usually associated with a local agricultural university, these centers serve as the ultimate link between the Indian Council of Agricultural Research and farmers, and aim to apply agricultural research in a practical, localized setting.

All KVKs fall under the jurisdiction of one of the 11 Agricultural Technology Application Research Institutes (ATARIs) throughout India. The Krishi Vigyan Kendra (KVKs)-
Agriculture Science Centre's, New agricultural technologies dissemination through KVKs with FLDs and OFTs by the KVK's Staffs and DRMR Scientists were adopted by the mustard growers to a considerable extent which may be due to better and adequate infrastructure training and demonstration facilities. The krishi Vigyan Kendra (KVKs) provides a strong training support for bringing about production break through in agriculture. Krishi Vigyan Kendras are functional in carrying out extension activities in accordance with government programme schedule and providing training support to raise the skill of the farmers which will help them to increase their farm productivity. Frontline demonstration (FLDs) is the long-term educational activity conducted by agricultural scientists in a systematic manner on farmers' field to show the worth of new practice/technology. It indicates FLDs and OFTs is proven extension intervention to demonstrate the production potential of improved technologies on farmers' field. [Sandeep patil et al., Indian Res. J. Extn. Edun. Vol.18, No. (4), October, 2018].

Indian Council of Agricultural Research (ICAR) had established Krishi Vigyan Kendras (KVKs)-'Agriculture Science Centre' across the India which is an institutional innovation for application of agricultural technologies on the farmer's field with the help of multidisciplinary team. The first KVK of the country was established in 1974 at erstwhile Pondicherry with mandate of imparting vocational trainings. The Krishi Vigyan Kendras actually originated as one of the Frontline Extension Systems of Indian Council of Agricultural Research (ICAR) that included National Demonstration (1966), Operational Research Projects (1974-75) and Lab to Land Programme (1979). All the first line extension services were merged with the KVKs during the 1990s with new structural 
and arrangements. There is need of close interaction between farmers, extension personnel and researchers in the participatory diagnosis of problems and developing location specific technologies. Therefore, the network of Krishi Vigyan Kendras has spread enormously in the country for promoting the extension educational approach rather than transfer of fixed package of recommendations. There are immense policy reforms in mandates and activities of KVK over a period of time. With a decision of establishing KVKs in all the rural districts of the country in Xth five-year plans, the KVK revised mandate. There is a wide network of $690 \mathrm{KVKs}$ in the country (ICAR, 2018). Therefore, the main mandate of the KVK is to plan and carry out on-farm trials (OFTs) to verify, test, validate and refine location 31 specific technologies developed by the National Agricultural Research System (NARS). The purpose is to have an appropriate technology which may be economically profitable, ecologically sustainable, technically feasible and culturally compatible. Another vital activity of KVK is to conduct the frontline demonstrations (FLDs) on flagship technologies developed by NARS on farmer's field (Kokate et al., 2016). The frontline demonstration is a long-term educational activity conducted by the KVK scientists in a systematic manner on farmers' field under his close supervision to show the worthiness of technology. Besides, KVK are building capacity of different stakeholders on niche areas of agricultural and allied sciences, and also acting as a Knowledge and Resource Center at district level. [Sandeep patil et. al., Indian Res. J. Extn. Edun. 18 (4), Oct., 2018].

India holds a significant share in world oilseed production. India is the second largest producer of groundnut after China and third largest producer of rapeseed after China and Canada (Directorate of Economics and Statistics, 2015). The area under major oilseeds viz., groundnut, sesamum, rapeseed, mustard, linseed, castor, soybean, cottonseed, sunflower, safflower and Nigerseed occupied 20 per cent net area sown across India (Ministry of Agriculture, 2014). It must, however, be noted that the production of oilseeds has always fallen short of national demand and overwhelm import of oilseeds has been ultimate option. The total oilseeds production in the country recorded during 2016-17 was about 35.40 Million Metric Tonne. There is limited scope for bringing an additional area under oilseeds in India. Therefore, increasing the oilseeds production is only option to meet the national requirement and which is primarily based on adoption of improved production technologies. Further, a wide regional variation in area, production and productivity of oilseeds is persists in India. Though, few states including Haryana, Madhya Pradesh, Rajasthan and West Bengal revealed increase in oilseed production through area expansion and productivity enhancement. The states like Maharashtra, Tamil Nadu and Himachal Pradesh holds potential to raise oilseed production through productivity improvement. Therefore, in these states KVKs were initiated with aim of organizing large scale FLD programs on oilseed crops for harnessing its potential. It is imperative to assess the effectiveness of front line demonstrations. [Sandeep patil et. al. Indian Res. Journal. Extn. Edun. 18 (4), October, 2018]

DRMR;-The Indian Council of Agricultural Research (ICAR) established the National Research Centre on Rapeseed-Mustard (NRCRM) on October 20, 1993, to carry out basic, strategic and applied research on rapeseed-mustard. Besides, generating basic knowledge and material, it also engages in developing ecologically sound and economically viable agro production and protection technologies. The Centre has also the responsibility to plan, coordinate and execute the research programmes through 
wide network of 22 main and sub-centres across the country, to augment the production and productivity of rapeseed-mustard. In February 2009, the ICAR re-designated NRCRM as the Directorate of Rapeseed Mustard Research (DRMR). DRMR:Directorate of Rapeseeds-Mustard Research station is located in near at Sewar, Bharatpur Division of Rajasthan in India.

Therefore, DRMR, Sewar under Bharatpur Region was purposively selected for consider the research study in this area. Front Line Demonstrations (FLDs) are being laid out regularly through the DRMR Scientists on the farmer's field to demonstrate the production potential of rapeseeds-mustard technologies. Challenge before DRMR is to increase the level of sufficiency in edible oils consumption in changing foods habit of ever-growing population in the country with increase or achieved the potential yields cultivars through developing ecologically sound and economically variables agro production and protection technologies for different agro climatic conditions.

Thus, the results of such study will be useful for State Department of Agriculture, Marketing Departments, State Agricultural Universities, Agricultural Research Stations, Krishi Vigyan Kendras as well as to the beneficiary farmers and non-beneficiary farmers to decide appropriate strategies and to make programmes for better production and to developed an economic environment for rapeseeds-mustard crops.

Keeping in view of the above facts in to consideration, the present research study was undertaken to entitled "Impact of Krishi Vigyan Kendras on Adoption of Recommended Mustard Production Technology by the Mustard Growers in Bharatpur Region of Rajasthan State, India". To assess the object to find out the Extent of
Adoption among-st the Mustard Growers (B. F. \& NB. F.) regarding Recommended Mustard Production Technology.

\section{Global Scenario}

The important rapeseed and mustard growing countries in the world are India, Canada, China, Pakistan, Bangladesh and Poland. India accounts for 6.34 million hectares $(19.29 \%)$ and 7.82 million tonnes $(11.12 \%)$ of the total acreage and production of rapeseeds and mustard in the world with third position after Canada and China. Rapeseeds and mustard group of crops are the second important edible oilseeds after groundnut. The total oilseeds production of the world is 463.30 million tonnes in which India account 31.01 million tonnes. Soybean, groundnut and rapeseeds \& mustard are the major oilseeds crops in India contributing nearly 79 per cent and 88 per cent to its total acreage and production, respect. Rapeseed and mustard contributed 24.20 per cent to total oilseeds production which is second after groundnut. [Source: Trade and Market Division, Food outlook, 2012-13 FAO, Food and Agriculture Organization, U.N., Rome. Italy.]

Rapeseeds-mustard is the third most important source of vegetables oils in the world, after soybean and oil palm. Rapeseeds \& mustard is widely grown in majority of Continents with largest area of 8.59 million hectares in Canada followed by 7.52 million hectares in China and >6.40 million hectares in India. However, the productivity of India is the lowest among the major rapeseeds-mustard growing countries. As against the World average of $1994 \mathrm{~kg} / \mathrm{ha}$, highest productivity of 3947 $\mathrm{kg} / \mathrm{ha}$ of Germany, the Indian average yields was only $1233 \mathrm{~kg} /$ ha during 2012-13. Longer crop duration and high carbon content in the soil are the major factors attributing to high productivity of rape-mustard in western part of the World. 
Global scenario is described under area production and productivity of the important countries during last 2 years is given in table 1.3.A [Source: Status Paper on Oilseeds, Decem.-2014. D.A\&C, MOA, GOI, (Krishi Bhawan), New Delhi]

\section{National Scenario}

$\mathrm{R} \& \mathrm{M}$ occupy second position after soybean in terms of production of oilseeds, but has first position in terms of vegetable oil (32\%).

Rapeseed comprising toria, brown sarson and yellow sarson are largely cross pollinated where as Indian mustard is largely self pollinated.

Indian mustard with largests hare of $75 \%$ is most climate resilient for rain fed /low irrigated/problem soils.

Toria, a short duration crop is grown as a catch crop in tarai part of UP, Haryana \& Eastern States.

Other cultivars like brown sarson and yellow sarson are under cultivation over a limited area in the Eastern part of the country. Area under this group has recently gone up.

Gobhi sarson is under cultivation over limited areas in HP, Jamu \& Kasmir Punjab under Irrigated ecologies.

High variation in oil content (31-46\%) provides scope for oil based marketing

Mustard (brassica jancea) is second most important oilseed crops after groundnut in India. India is the third largest producer of mustard crops where as china stands at first rank. The rapeseed-mustard production trends represent fluctuating scenario in India with all time high production of 8.17 million tonnes from 6.69 million hectares during 2010-11. Indian mustard (brassica jancea) is cultivated in Rabi season throughout the country mainly in Northern plain. The major rapeseedmustard growing states are Rajasthan, Haryana, Uttar Pradesh, Madya Pradesh and Gujarat, representing $80 \%$ of the national hectare. These states are contributing 86.72 per cent of total rapeseed-mustard production.

The country ranked third in areas (6.70 million hectares) of rapeseeds-mustard and third in its production (7.96 million tonnes) after Canada and China with a contribution of about 12.50 per cent in the total rapeseeds-mustard production of the world. In India, this group of crops is next only to soybean amongst different oilseeds crops with a share of 22.20 per cent in total area under oilseeds crops and 22.60 per cent in total oilseeds production (Kumar et. al., 2012). Rapeseeds-mustard group of crops is the third most important source of edible oils in the world after soybean and oil palm and with a share of 26.00 per cent is the largest consumed oils in the country amongst domestically produced edible oils. [(Meena et al., 2014) J. Oilseeds Res., Vol. 33, No.1: M, 2016 Pp.26-32]

The average contribution of rapeseedsmustard to the total oilseeds production in India was 24.20 per cent during 2012-13 years. Its average productivity was 1176 (kg/ha) as compared to $1135 \mathrm{~kg} / \mathrm{ha}$ of total oilseeds.

Though, rapeseeds-mustard ranks 2 nd in terms of production, after soybean, however due to more oils content (ranging from 35-45 \%) rapeseeds-mustard ranks $1 \mathrm{st}$ in terms of oils yields amongst all oilseeds crops. The rapeseeds-mustard production trends represent fluctuating scenario with an all time high production of 8.3 million tonnes from 6.90 million hectares during 2010-11 years.

The yields levels also have been variable from 1185 (kg/ha.) (2013-14) during the last 5 years. Highest productivity $1262(\mathrm{~kg} / \mathrm{ha})$ level was achieved during 2012-13 years. [Source: 
July-2015， Vision-2050， DRMR: (ICAR) Sewar, Bharatpur (Rajasthan) INDIA]

Rapeseeds-mustard is grown across the country, pre-dominantly in North, NorthWestern and North-Eastern Region of the country over an area of $>6.70$ million hectares. The area coverage under mustard is largely dependent on the late Kharif rains. Rajasthan, Madhya Pradesh, Haryana and Uttar-Pradesh contributes $>77$ per cent of area and about 82 per cent production of mustard in India. West Bengal, Gujarat and Assam also contribute significantly in mustard production. The States wise area, production and yields of rapeseedsmustard last 3 years are given in table 1.4.A [Source: Status Paper on Oilseeds, Decem.2014. D.A\&C, MOA, (GOI), Krishi Bhawan, New Delhi]

Six states in India, viz., Rajasthan, Uttar Pradesh, Madhya Pradesh, Haryana, West Bengal and Gujarat accounts for 88.00 per cent and 91.00 per cent of rapeseeds-mustard acreage and production, in the years 2011-12 respect. During the last five years, Rajasthan, Uttar Pradesh, Madhya Pradesh contributed $43.98 \%, 11.15 \%$ and $11.23 \%$ to acreage and production was $45.26 \%, 12.00 \%$ and 11.11 $\%$ respectively. The yields varied from $246 \mathrm{~kg}$ in Tamilnadu to $1609 \mathrm{~kg}$ in Haryana during 2011-12. Further recorded that by Gujarat (1577 kg.), Punjab (1333 kg.), Rajasthan (1187 kg.), Bihar (1151 kg.), Uttar Pradesh (1125 kg.), Madhya Pradesh (1108 kg.), and West Bengal (1049 kg.) had more than 1000 $\mathrm{kg} / \mathrm{ha}$ yields.(S:DOA,Vital Agri. Statistics, 2012Division-PantKrishi Bhawan,Jaipur, Rajasthan.)

Rajasthan, Madhya Pradesh, Uttar Pradesh, Haryana, West Bengal, and Gujarat States accounted for nearly 86.50 per cent area and 91.40 per cent production of rapeseedsMustard in the country during 2012-13 (Fig.1.2.A). The productivity of Haryana, Gujarat, Rajasthan, UP and MP was above
$1000 \mathrm{~kg} / \mathrm{ha}$. in the descending order. There was reduction in area and production of rapeseeds-mustard in Gujarat, West Bengal, Haryana, and Uttar Pradesh. States like Madhya Pradesh, West Bengal and Bihar showed increase in area and production. Maximum increase in production (48.21\%) was witnessed in Rajasthan, followed by Madhya Pradesh, Haryana, U.P. West Bengal, and Gujarat (Fig.1.2.B). However, the productivity levels were increased in all these States. This fluctuating trend in area, production and productivity requires multipronged strategies and technological interventions in upcoming years these areas need to be wide viable focused. [Source: July2015, Vision 2050, DRMR: (ICAR) Sewar, Bharatpur (Rajasthan) INDIA].

\section{State Scenario}

Rajasthan is an agrarian state, where eighty percent of the total population resides in rural area and largely dependent on agriculture as the source of their livelihood. The economy of this state is mostly depended on agriculture 22.50 per cent of state's GDP comes from agriculture. Recognize as the largest state of India, Rajasthan has cultivated area of almost 20 million hectares but due to some unavoidable circumstance on 20 per cent of the total cultivated area is irrigated. In Rajasthan, the productivity of rapeseedsmustard was $1266 \mathrm{~kg} / \mathrm{ha}$. from 31.37 lakh hectares area cultivated and total production was 39.65 lakh tonnes in 2013-14.(Balai, C.M. 2012.IRJEE, May-2012)

Indian mustard (Brassica jancea) (L.) Czern $\&$ Coss is the major oilseeds crops grown in Rajasthan during rabi season. In Rajasthan, the productivity of rapeseeds \& mustard was 1266 $\mathrm{kg} / \mathrm{ha}$. during 2013-14 from 31.37 lack hectares area under cultivation and total production was 39.65 lack tonnes. The yields levels also have been variables from 954 
$\mathrm{kg} / \mathrm{ha}$. to $1342 \mathrm{~kg} / \mathrm{ha}$. (2014) during the past five years. (S: DOA, Vital Agricultural Statistics, 2014 D-Pant Krishi Bhawan, Jaipur). In Rajasthan, rapeseeds \& mustard is cultivated over an area of 24.33 lack hectares with the production of 28.78 lack tonnes and average yields are $1183 \mathrm{~kg}$./ha. during the years 2014-15.

Rajasthan is rank first amongst all the states of India in terms of both area and production of rapeseeds-mustard with share of 44.30 per cent area and 47.20 per cent of production respectively. Rajasthan is the largest rapeseedmustard growing state and highest producer of oilseeds crops in the country with production of 36.50 million tonnes in $2012-13$ production years which is represented by 46.64 per cent of the total production in the country. (Anonymous, 2013) Realizing the importance of rapeseeds and mustard in India and the State, both Central and State government have endeavourer to increase production of mustard in the State through several incentives. Through adoption of recommended technologies by the farmers and by minimizing the production constraints it is possible. Therefore, it is very necessary to know the knowledge, adoption, attitude and constraints responsible for non-adoption of various recommended technology of rapeseeds and mustard cultivation by the farmers and efforts should be made to reduce the constraints for adoption of recommended production technology of mustard cultivation.

The present study is planned on rapeseedsmustard crops there has been a considerable increase in area from 24.34 million hectares in 2014-15 to 25.32 million hectares in 2015-16 and production has been increased from 28.79 million tonnes in 2014-15 to 32.52 million tonnes in 2015-16. The rapeseeds-mustard production trends represent fluctuating scenario with an all time higher production of 32.52 million tonnes from 25.32 million hectares acreage during 2015-16. The yields/productivity levels also have been variable ranging from $1183 \mathrm{~kg}$./ha. in 2014-15 to $1288 \mathrm{~kg}$./ha. in $2015-16$ during only one year. It is imperative to develop socioeconomic, technological and environmental strategies based on the field level observations for sustainable development of these crops with these points of view; the present investigation was under taken in Bharatpur Region of Rajasthan with the following specific objectives.

\section{Materials and Methods}

\section{Selection of Krishi Vigyan Kendras}

The present investigation was conducted in five selected Krishi Vigyan Kendra's from Bharatpur Region of Rajasthan. Each Krishi Vigyan Kendra is located at each district head quarter. KVK Navgaon (Alwar), KVK Kumher (Bharatpur) and KVK Unella (Dholpur) are working under Directorate of Extension Education, Jobner. However, the administrative control of Sri Karan Narendra Agricultural University, Jobner, DistrictJaipur, Rajasthan. KVK Kermoda (Sawaimadhopur) and KVK Hindoaun (Karoli) are working under Directorate of Extension Education, Kota. However, the administrative control of Agricultural University, Kota, Rajasthan. KVK Navgaon (Alwar), KVK Kumher (Bharatpur), KVK Unella (Dholpur) and KVK Hindoaun (Karoli) Districts come under Agro Climatic Zone III b of Rajasthan i.e. Flood Prone Eastern Plain Zone (III b). KVK Kermoda (Sawai-madhopur) District is situated in Agro-Climatic Zone $\mathrm{V}$ of Rajasthan.

Keeping the above facts in view, the present investigation an attempt has been made to measure the "Impact of Krishi Vigyan Kendras on Adoption of Recommended Mustard Production Technology by the 
Mustard Growers in Bharatpur Region of Rajasthan". Thus present research study has been conducted with the beneficiary farmers and non-beneficiary farmers regarding recommended mustard production technology in Bharatpur division. At present time, total numbers of $42 \mathrm{KVKs}$ are going on operation in all the tenth regions of Rajasthan State. This research work has been carried out, within five listed below KVKs purposively selected for the present research study from Bharatpur Region of Rajasthan viz.,Alwar, Bharatpur, Dholpur, Karouli \& Sawai-madhopur Districts of Rajasthan.

Bharatpur Region was purposively selected for the present investigation due to the following reasons:

Rajasthan is rank first amongst all the states of India in terms of both area and production of rapeseeds-mustard. Rajasthan state comprises of tenth regions viz., Jaipur, Sikar, Bharatpur, Bikaner, Sri-ganganagar, Jodhpur, Jalore, Kota, Udaipur and Bhilwara. In Rajasthan State, the rapeseeds and mustard crop is most popular oilseeds crops cultivated in Jaipur, Alwar, Bharatpur, Dholpur, Karouli, Sawaimadhopur, Sriganganagar, Jhunjhunu and Sikar Districts. In this state, its grown on area of 25,32,330 hectares with an annual production of 32,57,987 tonnes and productivity of $1287 \mathrm{~kg} / \mathrm{ha}$ in the years 2015 16.

Rapeseeds-mustard is the most important oilseeds crops grown in rabi season in Bharatpur Region of Rajasthan. Bharatpur Region occupies first rank in area, production and productivity of rapeseeds and mustard crop amongst the oilseeds crops in tenth regions of Rajasthan. It's mostly grown in five selected Districts of Bharatpur Division of Rajasthan. This region has covered 7,49,597 hectares of land. Whereas, an annual production of rapeseeds and mustard crop is 10,07,502 tonnes which is very high 1344 $\mathrm{kg} / \mathrm{ha}$ as compared to average national productivity 2015-16. (Source: Rajasthan Agricultural Statistics at a Glance. Jaipur, Rajasthan 2015-16)

DRMR:-Directorate of Rapeseeds-Mustard Research station is located in near at Sewar, Bharatpur Region of Rajasthan in India. Therefore, DRMR, Sewar under Bharatpur Region was purposively selected. Front Line Demonstrations (FLDs) are being laid out regularly by the DRMR Scientists on the farmer's field to demonstrate the production potential of rapeseeds-mustard technologies. Thus research study area was easily accessible to the investigator, he is bonafide resident of this region.

Limitation of time, money and available resources for this research study.

\section{Selection of the respondents/farmers}

25 , beneficiary farmers were selected from the list available at the each KVKs head quarter. Similarly, 25, non-beneficiary farmers were selected from the list available at the each KVKs head quarter. Thus, total numbers 50 mustard growers were selected from each KVK by the simple random sampling technique. In this way all five KVKs were included in the present investigation.

25, beneficiary farmers who are getting benefits from the KVK were randomly selected from each of the selected KVKs. Similarly, equal numbers of the nonbeneficiary farmers who are not getting benefits from the KVK were randomly selected from each of the selected KVKs. From these obtained lists, 125, beneficiary farmers and 125, non-beneficiary farmers were selected, in this way total 250 sample sizes for the present research study by using simple random sampling technique through proportionate. Thus, total sample sizes were consisted of 250 mustard growers from 
present research study. On the basis of specific objectives formed for the present research study, a suitable tool was developed.

The data were collected through personal interview method by interview schedule. Collected data were classified, tabulated, and statistically analyzed which led to the following salient findings. In order to test the validity of results various hypotheses were formulated and appropriate statistical tests were applied. The statistical tests applied were S.D., ' $z$ ' test, ' $t$ ' test and rank correlation. The levels of significance for acceptance or rejection of hypotheses were 5 percent and 1 percent level of significant.

\section{Results and Discussion}

Extent of adoption among the beneficiary farmers and non-beneficiary farmers about package of practices regarding recommended mustard production technology.

Adoption is a mental process through which an individual possess from first hearing about an innovation to final its adoption. In the modern era many new innovations are being invented by our agricultural scientists but all the innovations are not being adopted by many of the members in social system. It is generally assumed that if an individual has more knowledge about package of practices wise different aspects of technologies, he is likely to adopt the innovations early with higher speed. Adoption of an innovation depends on many factors viz., age and education, size of land holding, social participation, annual income, awareness and knowledge of adopters, innovativeness, characteristics, complexity and visibility of the innovations which may affect the adoption of improved mustard production technology. Thus, results in the extent of adoption with package of practices regarding recommended mustard production technology are narrated here under:
Distribution of the beneficiary farmers and non-beneficiary farmers according to their extent of adoption regarding recommended mustard production technology.

The range of adoption scores obtained by the beneficiary farmers and non-beneficiary farmers also divided into three extent of adoption categories in the form of frequency as well as percentage with package of practices wise recommended mustard production technology was assessed. For this, the respondents were divided into three adoption groups on the basis of mean and standard deviation and data were reset to find out the frequency and percentage in each category. The data related to the adoption of both the categories of farmers i.e., the beneficiary farmers and the non-beneficiary farmers indicates that the farmer's adoption of package of practices regarding recommended mustard production technology has wide gaps. In order to place the farmers into appropriate categories there for adoption scores were distributed as reported in table 1.

The data indicates in table 1 . shows that the total majority of farmers $136(54.40 \%)$ had from medium level (from 77 to 86 scores) extent of adoption category with regard to recommended mustard production technology. Further reported that the total majority of farmers $62(24.80 \%)$ had fall from high level (above 86.40 scores) extent of adoption category. Further observed that the total majority of farmers $52(20.80 \%)$ had from low level (below 76.13 scores) extent of adoption category regarding recommended mustard production technology.

The data reported in table 1 . shows that the majority 70 of the beneficiary farmers $(56.00$ $\%$ ) were having from medium level extent of adoption category with regard to recommended mustard production technology. Further reported that the majority 30 of the 
beneficiary farmers $(24.00 \%)$ were having from high level extent of adoption category. Further observed that the majority 25 of the beneficiary farmers $(20.00 \%)$ were having from low level extent of adoption category regarding recommended mustard production technology respectively.

Further data recorded in table 1. shows that the majority 66 of the non-beneficiary farmers $(52.80 \%)$ were having from medium level extent of adoption category with regard to recommended mustard production technology. Further reported that the majority 32 of the non-beneficiary farmers $(25.60 \%)$ were having from high level extent of adoption category. Further observed that the majority 27 of the non-beneficiary farmers $(21.60 \%)$ were having from low level extent of adoption category regarding recommended mustard production technology respectively.

These findings are similar in the compliance with the findings of Singh, Narpat (2004), Sachan et.al. (2005), Ashiwal (2006), Singh, N. et al., (2006), Tambade (2007), Chander et al., (2009), Singh, N. et al., (2009), Prasad, G. (2011), Sharma et.al. (2011), Badhala (2012), Dayanand et. al. (2012), Dudi and Meena (2012), Rai et.al. (2012), Asiwal et.al. (2013), Sharma et. al. (2013), Kumar, Amit et.al. (2016) and Rojh, Rajpal. et. al. (2016).

The extent of adoption among the beneficiary farmers and non-beneficiary farmers with regard to package of practices wise recommended mustard production technology

The data reported in table 2. shows that the overall extent of adoption with 67.54 MPS were found amongst the total majority of farmers with regard to recommended mustard production technology. This highest extent of adoption among the total majority of farmers about "Seed rate and recommended spacing" with 82.08 MPS; hence, it was rank first.
Further highest extent of adoption among the total majority of farmers followed towards "Fertilizer application" with 77.85 MPS was rank second. Further reported that the medium extent of adoption among the total majority of farmers reported in package of practices likes "Irrigation management" with 77.50 MPS, "Soil and field preparation" with 71.67 MPS, "Seed treatment" with 70.30 MPS, "Weed management" with 68.75 MPS and "Harvesting/threshing and storage" with 68.75 MPS were ranked Third, Fourth, Fifth, Sixth and Seven in ranks order. Further recorded that the medium extent of adoption among the total majority of farmers recorded in package of practices likes "Time of sowing" with 62.50 MPS and "HYV's varieties" with 62.50 MPS were ranked Eighth and Ninth in ranks order. Further observed that the lowest extent of adoption among the total majority of farmers observed in package of practices likes "Plant protection measures" with 59.38 MPS "Soil treatment" with 56.25 MPS and "Physiological aspects/practices" with 55.00 MPS were ranked Tenth, Eleventh and Twelfth in ranks order amongst the total majority of farmers regarding recommended mustard production technology respectively.

Further data recorded in table 2. indicates that in case of overall extent of adoption gaps (32.46 \%) were found amongst the total majority of farmers with regard to recommended mustard production technology. Further reported that the highest extent of adoption gaps among the total majority of farmers were reported in package of practices likes "Physiological aspects/practices" (45.00 $\%)$, "Soil treatment" (43.75\%), and "Plant protection measures" (40.62 \%). Further recorded that the medium extent of adoption gaps among the total majority of farmers were recorded in package of practices likes "Time of sowing" (37.50\%), "HYVs varieties" (37.50\%), "Weed management" (31.25\%), "Harvesting/threshing and storage" (31.25\%). 
Further observed that the lowest extent of adoption gaps were observed in package of practices likes "Seed treatment" (29.70\%), "Soil and field preparation" (28.33\%), "Irrigation management" (22.50\%), "Fertilizer application" (22.15\%), and "Seed rate and recommended spacing" (20.00\%) amongst the total majority of farmers regarding recommended mustard production technology respectively.

The data reported in table 2. shows that the overall extent of adoption with 72.73 MPS were found amongst the beneficiary farmers with regard to recommended mustard production technology. This highest extent of adoption among the beneficiary farmers about "Seed rate and recommended spacing" with 85.00 MPS; it was rank first. Further highest extent of adoption among the beneficiary farmers followed towards "Irrigation management" with 80.00 MPS was ranks second. Further reported that the medium extent of adoption among the beneficiary farmers reported in package of practices likes "Fertilizer application" with 79.42 MPS, "Soil and field preparation" with 76.67 MPS were ranked Third and Fourth in ranks order. Further recorded that the medium extent of adoption among the beneficiary farmers recorded in package of practices likes "Seed treatment" with 75.00 MPS, "Time of sowing" with 75.00 MPS "Weed management" with 75.00 MPS and "Harvesting/threshing and storage" with 75.00 MPS were ranked Fifth, Sixth, Seventh and Eighth in ranks order. Further reveals that the least extent of adoption among the beneficiary farmers reveal in package of practices likes "HYVs varieties" with 66.67 MPS, "Soil treatment" with 62.50 MPS were ranked Ninth and Tenth in rank order. Further observed that the lowest extent of adoption among the beneficiary farmers observed in package of practices likes "Plant protection measures" with 62.50 MPS and "Physiological aspects/practices" with 60.00
MPS were ranked Eleventh and Twelfth in rank order amongst the beneficiary farmers regarding recommended mustard production technology.

Further data recorded in table 2. indicates that in case of overall extent of adoption gaps $(27.27 \%)$ were found amongst the beneficiary farmers with regard to recommended mustard production technology. Further reported that the highest extent of adoption gaps among the beneficiary farmers were reported in package of practices likes "Physiological aspects/practices" (40.00\%), "Soil treatment" $(37.50 \%)$, and "Plant protection measures" $(37.50 \%)$. Further recorded that the medium extent of adoption gaps among the beneficiary farmers were recorded in package of practices likes "HYVs varieties" (33.33\%), "Seed treatment" (25.00\%), "Time of sowing" $(25.00 \%)$, "Weed management" (25.00\%), "Harvesting/threshing and storage" (25.00\%). Further observed that the lowest extent of adoption gaps were observed in package of practices likes "Soil and field preparation" $(23.33 \%)$, "Fertilizer application" (20.58 \%), "Irrigation management" (20.00\%) and "Seed rate and recommended spacing" (15.00\%) amongst the beneficiary farmers regarding recommended mustard production technology.

The data reported in table 2. shows that the overall extent of adoption with 62.35 MPS were found amongst the non-beneficiary farmers with regard to recommended mustard production technology. This highest extent of adoption among the non-beneficiary farmers about "Fertilizer application" with 76.35 MPS; hence, it was ranked first. Further highest extent of adoption among the non-beneficiary farmers followed towards "Seed rate and recommended spacing" with 75.00 MPS was rank Second. Further reported that the medium extent of adoption among the non-beneficiary farmers reported in package of practices likes "Irrigation management" with 75.00 MPS, 
"Soil and field preparation" with 66.67 MPS and "Seed treatment" with 65.60 MPS, were ranked Third, Fourth and Fifth in ranks order. Further recorded that the medium extent of adoption among the non-beneficiary farmers recorded in package of practices likes "Weed management" with 62.50 MPS and "Harvesting/threshing and storage" with 62.50 MPS were ranked Sixth and Seven in ranks order. Further reveals that the least extent of adoption among the non-beneficiary farmers reveal in package of practices likes 'HYV's varieties" with 58.33 MPS and "Plant protection measures" with 56.25 MPS were ranked Eighth and Ninth in ranks order. Further observed that the lowest extent of adoption among the non-beneficiary farmers observed in package of practices likes "Soil treatment" with 50.00 MPS, "Time of sowing" with 50.00 MPS and "Physiological aspects /practices" with 50.00 MPS were ranked Tenth, Eleventh and Twelfth in ranks order amongst the non-beneficiary farmers regarding recommended mustard production technology respectively.

Further data recorded in table 2. indicates that in case of overall extent of adoption gaps $(37.65 \%)$ were found amongst the nonbeneficiary farmers with regard to recommended mustard production technology. Further reported that the highest extent of adoption gaps among the non-beneficiary farmers were reported in package of practices likes "Soil treatment" (50.00\%), "Time of sowing" (50.00\%) and "Physiological aspects/practices" (50.00 \%). Further recorded that the medium extent of adoption gaps among the non-beneficiary farmers were recorded in package of practices likes "Plant protection measures" (43.75 \%), "HYVs varieties" (41.67\%), "Weed management" $(37.50 \%)$, "Harvesting/threshing and storage" $(37.50 \%)$. Further observed that the lowest extent of adoption gaps were observed in package of practices likes "Seed treatment" $(34.40 \%)$, "Soil and field preparation" $(33.33 \%)$, "Seed rate and recommended spacing" (25.00\%) "Irrigation management" $(25.00 \%)$ and "Fertilizer application" (23.65 $\%)$, amongst the non-beneficiary farmers regarding recommended mustard production technology respectively.

These findings are similar in conformity with the findings of Singh, Narpat (2004), Sachan et.al. (2005), Ashiwal (2006), Singh, N. et al., (2006), Tambade (2007), Chander et al., (2009), Singh, N. et.al. (2009), Prasad, Gopal (2011), Sharma et.al. (2011), Badhala (2012), Dayanand et al., (2012), Dudi and Meena (2012) Rai et.al. (2012), Asiwal et.al. (2013), Sharma et al., (2013), Kumar, Amit et.al. (2016), and Rojh, Rajpal et.al. (2016) who found that beneficiary farmers had higher adoption than the non-beneficiary farmers also similar trends of adoption between beneficiary and non-beneficiary farmers.

Comparison of extent of adoption between the beneficiary and non-beneficiary farmers with package of practices regarding recommended mustard production technology. The significant difference between the extent of adoption was analyzed with the help of ' $Z$ ' test. The obtained results have been presented in table 3 .

$\mathrm{H}_{0}$ There is no significant difference between the extent of adoption among the beneficiary farmers and non-beneficiary farmers with regard to recommended mustard production technology.

$\mathrm{H}_{1}$ There is a significant difference between the extent of adoption among the beneficiary farmers and non-beneficiary farmers with regard to recommended mustard production technology. 
Table.1 Selection of Krishi Vigyan Kendras and Rapeseeds-Mustard Growers from Bharatpur Region of Rajasthan

\begin{tabular}{|c|c|c|c|}
\hline Selected Division & Selected KVKs & \multicolumn{2}{|c|}{ No. of Rapeseeds-Mustard Growers } \\
\hline \multirow{3}{*}{ Bharatpur Region } & Alwar & 25 & 25 \\
\cline { 2 - 4 } & Bharatpur & 25 & 25 \\
\cline { 2 - 4 } & Dholpur & 25 & 25 \\
\cline { 2 - 4 } & Karoli & 25 & 25 \\
\cline { 2 - 4 } & Sawai-madhopur & 25 & 25 \\
\hline Total & $\mathbf{5}$ KVKs & $\mathbf{1 2 5}$ & $\mathbf{1 2 5}$ \\
\hline
\end{tabular}

Table. 2 Distribution of the beneficiary farmers and non-beneficiary farmers according to their extent of adoption regarding recommended mustard production technology.

\begin{tabular}{|c|l|c|c|c|c|c|c|}
\hline \multirow{2}{*}{$\begin{array}{c}\text { S. } \\
\text { No. }\end{array}$} & \multicolumn{1}{|c|}{ Extent of adoption } & \multicolumn{2}{|c|}{$\begin{array}{c}\text { Beneficiary } \\
(\mathbf{N = 1 2 5})\end{array}$} & \multicolumn{2}{c|}{$\begin{array}{c}\text { Non-beneficiary } \\
(\mathbf{N = 1 2 5})\end{array}$} & \multicolumn{2}{c|}{$\begin{array}{c}\text { Total } \\
\text { (N=250) }\end{array}$} \\
\cline { 3 - 8 } & & F & $\%$ & F & $\%$ & F & $\%$ \\
\hline 1. & Low (below 76.13 score) & 25 & 20.00 & $\mathbf{2 7}$ & $\mathbf{2 1 . 6 0}$ & $\mathbf{5 2}$ & $\mathbf{2 0 . 8 0}$ \\
\hline 2. & Medium (from 77 to 86 score) & 70 & 56.00 & $\mathbf{6 6}$ & $\mathbf{5 2 . 8 0}$ & $\mathbf{1 3 6}$ & $\mathbf{5 4 . 4 0}$ \\
\hline 3. & High (above 86.40 score) & 30 & 24.00 & $\mathbf{3 2}$ & $\mathbf{2 5 . 6 0}$ & $\mathbf{6 2}$ & $\mathbf{2 4 . 8 0}$ \\
\hline & Total & $\mathbf{1 2 5}$ & $\mathbf{1 0 0 . 0 0}$ & $\mathbf{1 2 5}$ & $\mathbf{1 0 0 . 0 0}$ & $\mathbf{2 5 0}$ & $\mathbf{1 0 0 . 0 0}$ \\
\hline
\end{tabular}

Mean $=81.26 \quad$ S.D. $=\mathbf{5 . 1 3} \quad$ F= Frequency; $\%=$ Percentage

Table.3 The extent of adoption among the beneficiary farmers and non-beneficiary farmers with regard to package of practices wise recommended mustard production technology.

\begin{tabular}{|c|c|c|c|c|c|c|c|}
\hline \multirow[t]{2}{*}{$\begin{array}{c}\text { S. } \\
\text { No. }\end{array}$} & \multirow[t]{2}{*}{ Package of practices } & \multicolumn{2}{|c|}{$\begin{array}{l}\text { Beneficiary } \\
(\mathrm{N}=125)\end{array}$} & \multicolumn{2}{|c|}{$\begin{array}{l}\text { Non-Beneficiary } \\
(\mathbf{N}=125)\end{array}$} & \multicolumn{2}{|c|}{$\begin{array}{c}\text { Total } \\
(\mathbf{N}=\mathbf{2 5 0})\end{array}$} \\
\hline & & MPS & AG & MPS & AG & MPS & AG \\
\hline 1. & HYVs varieties & 66.67 & 33.33 & 58.33 & 41.67 & 62.50 & 37.50 \\
\hline 2. & Soil and field preparation & 76.67 & 23.33 & 66.67 & 33.33 & 71.67 & 28.33 \\
\hline 3. & Soil treatment & 62.50 & 37.50 & 50.00 & 50.00 & 56.25 & 43.75 \\
\hline 4. & Seed treatment & 75.00 & 25.00 & 65.60 & 34.40 & 70.30 & 29.70 \\
\hline 5. & Time of sowing & 75.00 & 25.00 & 50.00 & 50.00 & 62.50 & 37.50 \\
\hline 6. & $\begin{array}{l}\text { Seed rate and recommended } \\
\text { spacing }\end{array}$ & 85.00 & 15.00 & 75.00 & 25.00 & 80.00 & 20.00 \\
\hline 7. & Fertilizer application & 79.42 & 20.58 & 76.35 & 23.65 & 77.85 & 22.15 \\
\hline 8. & Irrigation management & 80.00 & 20.00 & 75.00 & 25.00 & 77.50 & 22.50 \\
\hline 9. & Weed management & 75.00 & 25.00 & 62.50 & 37.50 & 68.75 & 31.25 \\
\hline 10. & Plant protection measures & 62.50 & 37.50 & 56.25 & 43.75 & 59.38 & 40.62 \\
\hline 11. & Physiological aspects /practices & 60.00 & 40.00 & 50.00 & 50.00 & 55.00 & 45.00 \\
\hline 12. & $\begin{array}{l}\text { Harvesting/threshing and } \\
\text { storage }\end{array}$ & 75.00 & 25.00 & 62.50 & 37.50 & 68.75 & 31.25 \\
\hline & Over all & 72.73 & 27.27 & 62.35 & 37.65 & 67.54 & 32.46 \\
\hline
\end{tabular}


$\mathbf{r}_{\mathrm{s}}=$ Rank correlation; $\quad * *$ Significant at $1 \%$ level

Table.4 Comparison of extent of adoption between the beneficiary farmers and non-beneficiary farmers with package of practices regarding recommended mustard production technology.

\begin{tabular}{|c|c|c|c|c|c|c|}
\hline \multirow[t]{2}{*}{$\begin{array}{c}\text { S. } \\
\text { No. }\end{array}$} & \multirow[t]{2}{*}{ Package of practices } & \multicolumn{2}{|c|}{$\begin{array}{c}\text { Beneficiary } \\
(\mathrm{N}=125)\end{array}$} & \multicolumn{2}{|c|}{$\begin{array}{c}\text { Non-Beneficiary } \\
(\mathrm{N}=125)\end{array}$} & \multirow[t]{2}{*}{ 'Z' value } \\
\hline & & Mean \pm & S.D. & Mean \pm & S.D. & \\
\hline 1. & HYVs varieties & 8.00 & 0.71 & 7.00 & 0.62 & $11.78 *$ \\
\hline 2. & Soil and field preparation & 4.60 & 0.41 & 4.00 & 0.36 & $12.10^{*}$ \\
\hline 3. & Soil treatment & 5.00 & 0.45 & 4.00 & 0.36 & $19.52 * *$ \\
\hline 4. & Seed treatment & 3.00 & 0.27 & 2.62 & 0.23 & $12.60 *$ \\
\hline 5. & Time of sowing & 3.00 & 0.27 & 2.00 & 0.18 & $34.80 * *$ \\
\hline 6. & Seed rate and recommended spacing & 10.20 & 0.91 & 9.00 & 0.64 & $12.05^{*}$ \\
\hline 7. & Fertilizer application & 27.00 & 2.41 & 25.96 & 2.31 & $3.49 *$ \\
\hline 8. & Irrigation management & 3.20 & 0.29 & 3.00 & 0.27 & $5.71 *$ \\
\hline 9. & Weed management & 6.00 & 0.53 & 5.00 & 0.45 & $16.07 * *$ \\
\hline 10. & Plant protection measures & 10.00 & 0.89 & 9.00 & 0.80 & $9.91 *$ \\
\hline 11. & Physiological aspects /practices & 6.00 & 0.53 & 5.00 & 0.45 & $16.07 * *$ \\
\hline 12. & Harvesting/threshing and storage & 6.00 & 0.53 & 5.00 & 0.45 & $16.07 * *$ \\
\hline & Over all & & & & & \\
\hline
\end{tabular}

It is clear from this table 3. that the calculated ' $Z$ ' value was greater than its tabulated value at 5 per cent level of significance for all 12 packages of practices with regard to recommended mustard production technology Thus, the rejection of null hypothesis and accepted the alternative hypothesis accept and leading to conclusion that there were significant difference in extent of adoption between the beneficiary farmers and nonbeneficiary farmers with regard to all 12 packages of practices wise recommended mustard production technology in the present research study area.

Thus, this is proved evidently that the more adoption among the beneficiary farmers as compared to the non-beneficiary farmers with regard to recommended mustard production technology. The significant difference between the beneficiary farmers and nonbeneficiary farmers were found with regard to extent of adoption with regard to recommended mustard production technology in the study area. It may be because of the reason that the FLD's were conducted on the field of the beneficiary farmers from both the organizations and institutions likes as DRMR, Scientists and SMSs of K.V.K's. They have also provided necessary guidance, literature and training to the beneficiary farmers from both the organizations and institutions likes as DRMR, Scientists Sewar (Bharatpur) and SMSs of K.V.K's Alwer, Bharatpur, Dholpur, Karoli and Sawai madhopur. It may be due to the facts that various extension activities like the beneficiary farmers being in continuous touch with the DRMR and K.V.K. personnel's might have acquired sufficient knowledge and skills pertaining to adoption with regard to recommended mustard production technology. Thus, they are more likely to practice the learnt skills on their fields. 
Extent of adoption among-st the mustard growers regarding recommended mustard production technology.

This study was undertaken in Bharatpur Region of Rajasthan State, to find out that the extent of adoption amongst the mustard growers on a sample size of 250 respondents (125, beneficiary farmers and 125 , nonbeneficiary farmers) from both the category of mustard growers regarding recommended mustard production technology. The study highlights that the maximum number, more than half of the respondents were found the total majority of farmers $136(54.40 \%)$, the majority 70 of the beneficiary farmers $(56.00$ $\%)$ and the majority 66 of the non-beneficiary farmers $(52.80 \%)$ were having from medium level extent of adoption groups category. Further reported that the total majority of farmers $62(24.80 \%)$, the majority 30 of the beneficiary farmers $(24.00 \%)$ and the majority 32 of the non-beneficiary farmers $(25.60 \%)$ were having from high level extent of adoption groups category. Further observed that the total majority of farmers $52(20.80 \%)$, the majority 25 of the beneficiary farmers $(20.00 \%)$ and the majority 27 of the nonbeneficiary farmers $(21.60 \%)$ were having from low level extent of adoption groups category with regard to recommended mustard production technology.

Finding recorded from the research study that the overall extent of adoption with 67.54 MPS followed overall extent of adoption gaps $(32.46 \%)$ were found among the total majority of farmers. Further reported that the overall extent of adoption with 72.73 MPS while, overall extent of adoption gaps (27.27 $\%$ ) were found among the beneficiary farmers. Further observed that the overall extent of adoption with 62.35 MPS whereas, overall extent of adoption gaps $(37.65 \%)$ were found among the non-beneficiary farmers regarding recommended mustard production technology.
The data high light in table 2. Indicated that the highest extent of adoption exists in package of practices likes "Seed rate and recommended spacing" and "Irrigation management" hence, it were ranked first and second. Further reported that the medium extent of adoption in package of practices likes "Fertilizer application", "Soil and field preparation" were ranked Third and Fourth in ranks order. Further recorded that the medium extent of adoption in package of practices likes "Seed treatment", "Time of sowing", "Weed management", and "Harvesting/threshing and storage" were ranked Fifth, Sixth, Seventh and Eighth in ranks order. Further observed that the lowest extent of adoption in package of practices likes "HYVs varieties", "Soil treatment", "Plant protection measures" and "Physiological aspects/practices" were ranked Ninth, Tenth, Eleventh and Twelfth in ranks order. On the other hand, Further reported that the highest extent of adoption gaps exists in package of practices likes "Physiological aspects/practices", "Soil treatment" and "Plant protection measures". Further recorded that the medium extent of adoption gaps in package of practices likes "HYVs varieties", "Seed treatment", "Time of sowing", "Weed management", "Harvesting/threshing and storage". Further observed that the lowest extent of adoption gaps in package of practices likes "Soil and field preparation", "Fertilizer application", "Irrigation management" and "Seed rate \& recommended spacing" amongst both the category of farmers regarding recommended mustard production technology.

This finding reveals that the calculated ' $Z$ ' value was greater than its tabulated value at 5 per cent level of probability for all 12 packages of practices with regard to recommended mustard production technology. Thus, the rejection of null hypothesis and 
accepted the alternative hypothesis leading to conclusion that there were significant difference in extent of adoption between the beneficiary farmers and the non-beneficiary farmers with regard to all 12 packages of practices wise recommended mustard production technology in the research study area.

Thus, this is proved evidently, significant difference between beneficiary farmers and non-beneficiary farmers with respect to extent of adoption of recommended mustard production technology in the study area. It indicates that the beneficiary farmers had higher extent of adoption as compared to nonbeneficiary farmers. Significant association for Education level, social participation, extension participation, Source of information utilized, Economic motivation, and Irrigation potentiality had positively and significantly associated with the extent of adoption. On the other hand, non-significant association for age, size of land holding and risk orientation had negatively and non-significantly associated with the extent of adoption amongst both the category of farmers regarding recommended mustard production technology. It may be because of the reason that the FLDs were conducted on the field of the beneficiary farmers from both the organizations and institutions likes as DRMR, Scientists and SMSs of K.V.K's. They have also provided necessary guidance, literature and training to the beneficiary farmers from both the organizations and institutions likes as DRMR, Sewar, Bharatpur and K.V.K's, Alwer, Bharatpur, Dholpur, Karoli and Sawai madhopur.

\section{References}

Anonymous, 2015-16. Agricultural Statistics at a Glance. Department of Agriculture, and Cooperation, Directorate of Economics and Statistics, Ministry of Agricultural,
(Govt. of India) New Delhi. retrievedfromeands.dacnet.nic.in.

Anonymous, 2015-16. DOA, Rajasthan Agricultural Statistics at a Glance. Commissionerate of Agriculture, (Govt. of Raj.) Jaipur, Rajasthan.

Anonymous, 2012. DOA, Vital Agricultural Statistics, Division, Pant Krishi Bhawan, (Govt. of Raj.) Jaipur, Rajasthan.

Anonymous, 2014. DOA, Vital Agricultural Statistics, Division, Pant Krishi Bhawan, (Govt. of Raj.) Jaipur, Rajasthan.

Anonymous, 2012-13. FAO-STAT Trade and Market Division, Food outlook 201213. Food and Agriculture Organization (FAO) of the United Nations, Rome. Italy. "Agricultural Statistics databases". Available at http://faostat.fao.org.

Anonymous, 2014. Status paper on Oilseeds, Department of Agriculture and Cooperation, Ministry of Agricultural, (Govt. of India) (Krishi Bhawan), New Delhi, India. (http://nmoop.gov.in/Misc/Status Paper.pdf).

Anonymous, 2015. Vision 2050, [Directorate of Rapeseed-Mustard Research: DRMR: (ICAR) Sewar, Bharatpur 321 303 (Rajasthan) India].

Ashiwal, B.L. (2006). "Impact of Front Line Demonstration on adoption of improved mustard production technologies among the farmers of Laxmangarh Panchayat Samiti of Sikar District Rajasthan".M.Sc.(Ag.)Thesis (unpub.),S.K.Raj.Agri.Univ.,Bikaner,c ampus-Jobner.

Asiwal, B.L. Singh, Sangram and Sharma N.K. (2013). "Adoption gaps and constraints in adoption of improved mustard production technology in semi arid region of Rajasthan". Raj. J. Extn. 
Edun. \& R.D. Vol. 21, 105-108, 2013.

Badhala, B.S. (2012). "Impact of Front Line Demonstrations on Adoption of Groundnut Production Technologies by the Farmers of Rajasthan". Ph.D. (Ag.) Thesis (Unpub.), S.K. Rajasthan Agricultural University, Bikaner, campus-Jobner.

Balai, C.M. Meena, R.P. Meena, B.L. and Bairwa R.K. 2012. "Impact of Front Line Demonstration on RapeseedMustard Yields Improvement". Indian Res. J. Extn. Edun. Vol. 12, No.2: May, 2012.

Bhardwaj, V. 2013. "Overview of Indian Oilseed Sector". National Council of Applied Economic Research (NCAER) The Solvent Extractors' Association of India (SEA) www.ncaer.org accessed on 20.11.2013

Chander, S. Nand, H. and Sharma, K.P. (2009). "Knowledge, adoption and yield level of groundnut production technology". AIAEE Vol. 16, No. (2): 18-21.

Dayanand, Verma, R.K. and Mehta, S.M. (2012). "Boosting Mustard Production through Front Line Demonstrations". Indian Res. J. Extn. Edun. Vol. 12, No. (3): Sep., 2012.

Dudi, Aishwary and Meena, M.L. (2012). "Adoption of Improved Mustard Production Technology in pali District of Rajasthan". Inter. J. of Extn. Edun. Vol. 8, No.5-8: ISSH: 32, 19-71, 88 2012.

Gopal, Prasad. (2011). "Impact of Front Line Demonstrations on Knowledge, Attitude and Adoption of Recommended Production Technology of Mustard Cultivation by the Farmers in Bharatpur District of Rajasthan". M.Sc.(Ag.) Thesis (Unpub.),RAU, Bikaner, Campus:Jobner.

Kumar, Amit. Bareth, L.S. and Samota, Santosh Devi (2016). "Impact of
Agricultural Technology Management Agency on Adoption of Mustard Production Technology by Beneficiary and Non-Beneficiary Farmers". Indian J. Extn. Edun. \& R.D.Vol.24: 2016.

Kumar, Rakesh. Slathia, P.S. Peshin, Rajinder. Gupta, S.K. and Nain, M.S. 2016. "A Test to Measure the Knowledge of Farmers about Rapeseed Mustard Cultivation". Indian J. of Extn. Edun. Vol. 52 No. 3 \& 4, 2016. Pp. 157-159.

Meena, C.P. Chauhan, J.S. Singh, M. Singh, K.H. Rathore, S.S. and Meena, M.L. 2014. Genetic parameters and correlations for seed yield and morphological characters in Indian mustard [Brassica juncea (L.) Czern. \& Coss.] J. of Oilseeds Research, Vol. 31 No.2: Pp.114-117.

Rojh, Rajpal. Hanuman, Ram. Sharma, S.K. and Prasad, Dwarka (2016). "Knowledge and Adoption of Improved Cultivation Practices of Groundnut by the Farmers of Bikaner District of Rajasthan". Indian J. Extn. Edun. \& R.D. Vol.24: 2016.

Sachan, R.C. and Sharma, A.K. (2005). "Yield Gap Estimation with Reference to Level of Adoption of Recommended Mustard Technologies". Raj. J. Extn. Edun. Vol.12-13, No.(1): 19-26.

Sandeep, Patil. Mahesh, Mahale. Sudesh kumar, Chavan and Vaibhav, Shinde (2018). "Impact of Frontline Demonstrations on Oilseed Crops in Konkan Region of Maharashtra". Indian Res. J. Extn. Edun. Vol.18 No.4, October, 2018.

Sharma, A.K. Chauhan, J. and Kumar, Vinod (2013). "Perception Dynamics of Farmers Affecting Sustainability of Mustard Production: An Analytical Study". Indian Res. J. Extn. Edun. Vol.13, No.(3): Sep., 2013.

Sharma, A.K. Kumar, V. Jha, S.K. and Sachan, R.C. (2011). "Front Line 
Demonstrations on Indian Mustard an Impact Assessment". Indian Res. J. Extn. Edun. Vol. 11, No.(3): 2531,2011 .

Singh, N. (2004). "Knowledge and adoption of recommended technology mustard cultivation in Jhunjhunu District of Rajasthan". M.Sc. (Ag.) Thesis (Unpub.), RAU, Bikaner, Campus: S.K.N. College of Agriculture-Jobner.

Singh, N. Bareth, L.S. and Sharma, A.K. (2009). "Impact of Front Line Demonstration on Adoption of Mustard Production Technology by the
Farmers. Souvenir, November-2009. RSEE, MPUAT, Udaipur, PP-111-112.

Singh, N. Lal, Hanuman. and Sharma, Poonam. (2006). "Adoption of recommended mustard production technology by the farmers". Raj. J. Extn. Edun. Vol. 14, No.(1): 149-151.

Tambade, L.R. (2007). A study on knowledge, adoption and yield gap analysis of farmer's under-taking Front Line Demonstration (FLD) on oil-seed \& pulses in Solapur District. Unpub. Ph.D. Thesis, YCMOU, Nashik.

\section{How to cite this article:}

Meena S. R. and Sharma Y. K. 2019. Extent of Adoption and Adoption Gaps among-st the Mustard Growers (B. F. \& NB. F.) regarding Recommended Mustard Production Technology. Int.J.Curr.Microbiol.App.Sci. 8(09): 1718-1735. doi: https://doi.org/10.20546/ijcmas.2019.809.195 